
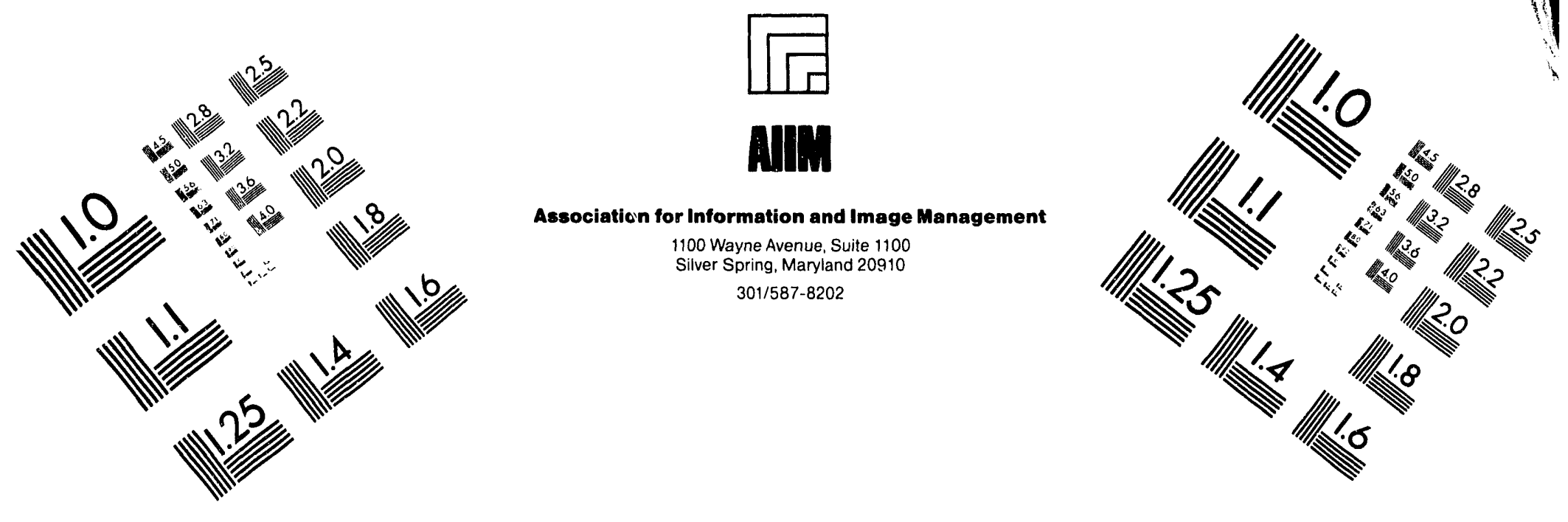

\title{
Centimeter
}

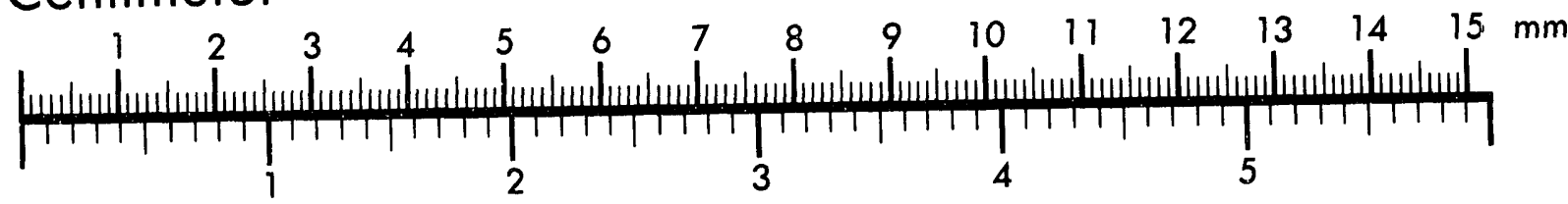
Inches
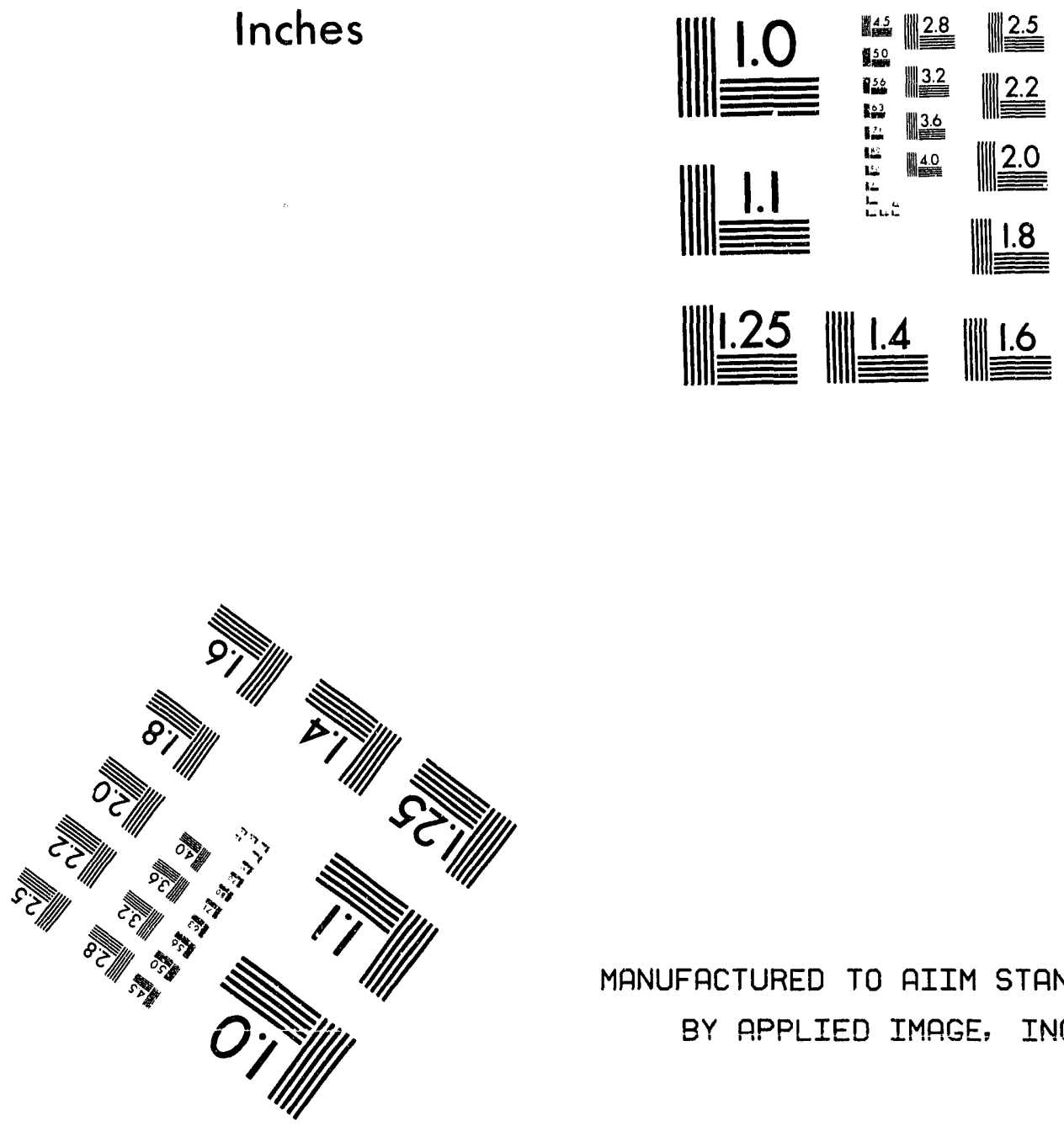

MANUFACTURED TO AIIM STANDARDS

BY APPLIED IMAGE, INC.

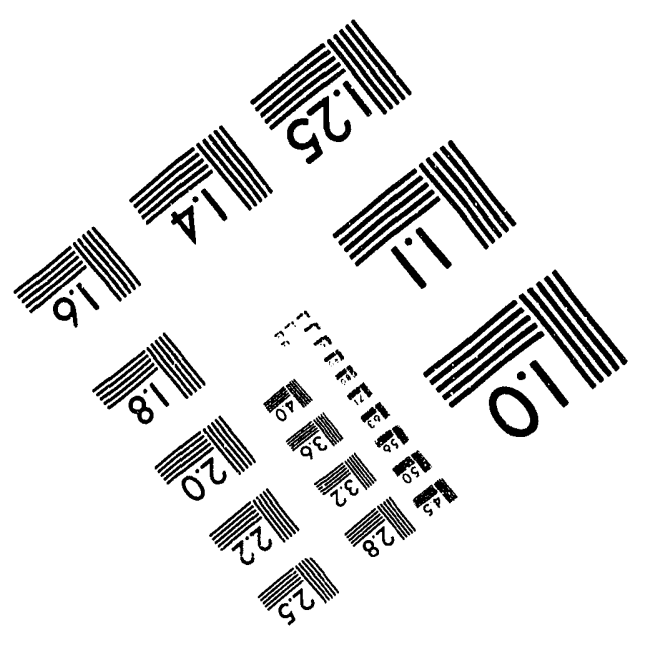



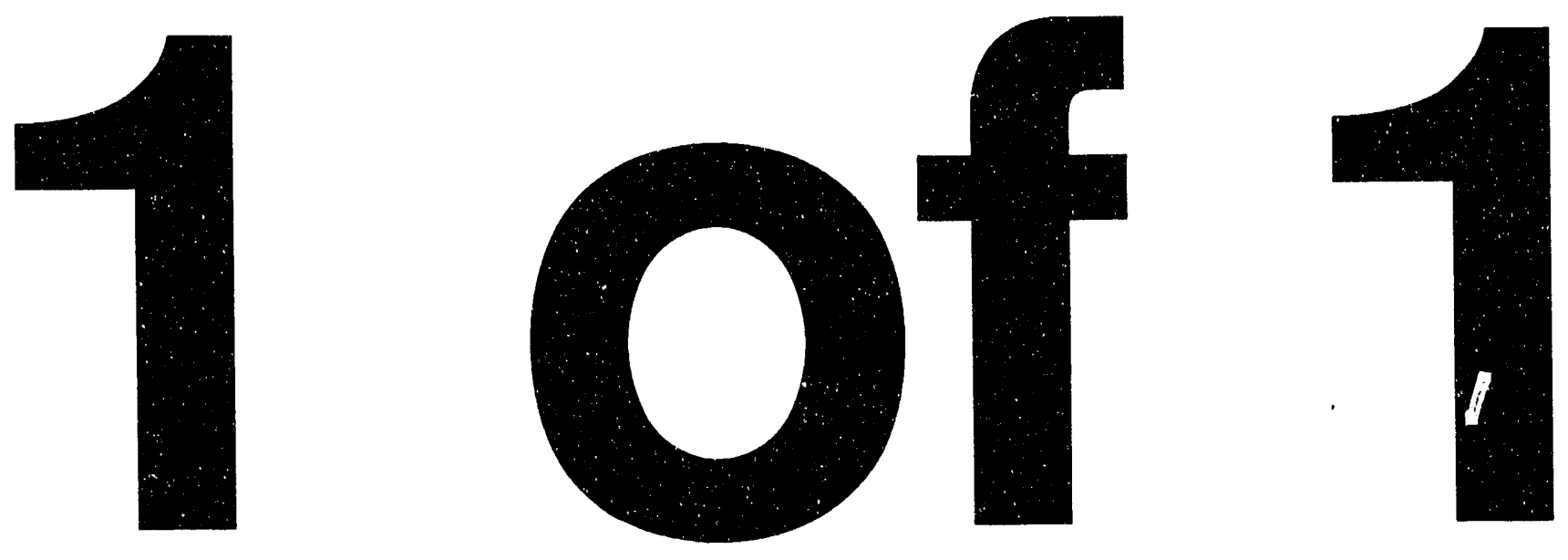


\title{
Conf- $9305136--4$
}

\section{TECHNOLOGY DEVELOPMENT FOR RECIRCULATING HEAVY-ION ACCELERATORS}

\author{
Mark A. Newton and Hugh C. Kirbie \\ Lawrence Livermore National Laboratory, University of Califormia
P.O. Box 5508, L-440, Livermore California 94550, USA
}

This paper was prepared for submittal to the
Proceedings of the International Symposium on Heavy Ion Inertial Fusion

Frascati, Italy

May 25-28, 1993

May 18, 1993

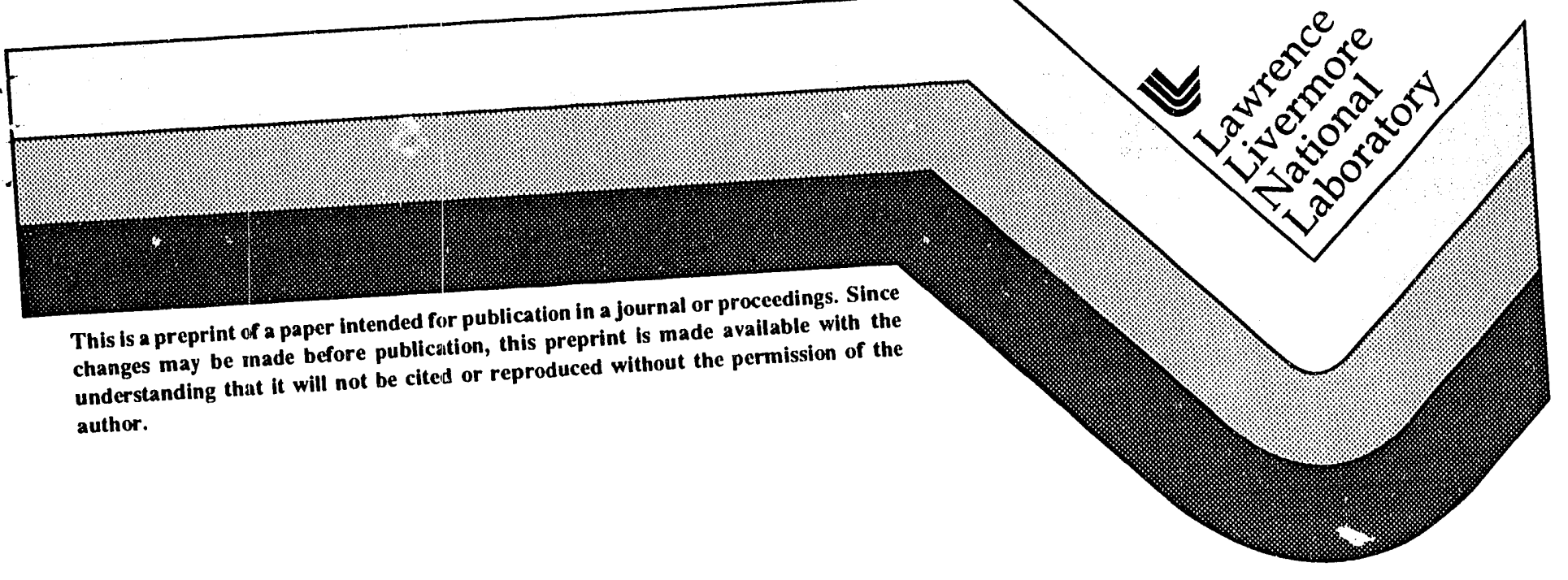




\section{DISCLAIMER}

This document was prepared as an account of work sponsored by an agency of the United States Government. Neither the United States Government nor the University of California nor any of thcir employees, makes any warranty, express or implied, or assumes any legal liability or responsibility for the accuracy, completeness, or usefulness of any information, apparatus, product, or process disclosed, or represents that its use would not infringe privately owned rights. Reference herein to any specific commercial products, process, or service by trade name, trademark, manufacturer, or otherwise, does not necessarily constitute or imply its endorsement, recommendation, or favoring by the United States Govemment or the University of Califomia. The views and opinions of authors expressed herein do not necessarily state or reflect those of the United States Government or the University of California, and shall not be used for advertising or product endorsement purposes. 


\title{
TECHNOLOGY DEVELOPMENT FOR RECIRCULATING HEAVY-ION ACCELERATORS
}

\author{
M. A. Newton and H. C. Kirbie \\ Lawrence Livermore National Laboratory, University of California \\ P.O. Box 5508, L-440, Livermore, California 94550, USA
}

The "recirculator," a recirculating heavy-ion accelerator has been identified as a promising approach for an inertial fusion driver. System studies have been conducted to evaluate the recirculator on the basis of feasibility and cost. The recirculator has been shown to have significant cost advantages over other potential driver schemes, but some of the performance requirements exceed the capabilities of present technology. The system studies identified the high leverage areas where advances in technology will significantly impact the cost and performance of a recirculator. One of the high leverage areas is the modulator system which generates the acceleration potentials in the induction cells. The modulator system must be capable of generating the acceleration potentials at peak repetition rates in excess of $100 \mathrm{kHz}$ with variable pulse widths. LLNL is developing a modulator technology capable of driving induction cells using the latest in solid state MOSFET technology.[1] A small scale modulator has been built and tested to prove the concept and the next version is presently being designed. Our objective is to demonstrate a modulator operating at $5 \mathrm{kV}, 1 \mathrm{kA}$, with $0.2-1 \mu \mathrm{s}$ pulse widths while driving an induction cell at $>100 \mathrm{kHz}$ within the next year. This paper describes the recirculator, the technology requirements necessary to implement it and the modulator system development that is being pursued to meet these requirements.

PACS Numbers: 28.52.Av, 84.30.Jc, and 84.70.+p 


\section{INTRODUCTION}

\subsection{Background on HIF}

Heavy Ion Fusion (HIF) is one of the promising alternatives for using inertial fusion to generate commercial electrical power in the 21st century. There have been numerous studies that evaluate the different types of accelerators that might be used as "drivers" for heavy-ion-driven inertial fusion. Systems studies conducted at Lawrence Livermore National Laboratory (LLNL) have shown that a recirculating induction accelerator, "recirculator," can provide substantial reductions in driver costs over the more conventional linear induction accelerator.[2]

\subsection{What is a recirculator and how is it different?}

A recirculator is an induction accelerator which accelerates the particles and bends them in a closed path. The methods for acceleration and focusing are nearly identical to a linear induction accelerator where induction accelerator cells couple the accelerating potential to the beam and quadrupole magnets provide the focusing. Unlike the linear machine, the acceleration and focusing components are re-used many times to accelerate the ions to their final energy resulting in a significant reduction in the number of acceleration and focusing components. In a recirculator however, dipole magnets and power supplies are required to bend the ion beam, which are unnecessary in a linear machine.

While the recirculator may afford significant cost reductions through the reuse of many of the induction accelerator components, it does require more advanced technology which partially offsets the cost savings. One of these areas of technology that is critical to the feasibility of a recirculator is the modulator system which generates the pulses that accelerate the ion beams. This paper will describe the modulator characteristics required by a recirculator and the work that is being done to achieve these characteristics for near term experiments.

\section{MODULATOR REQUIREMENTS}

\subsection{Performance requirements}

Re-use of the induction accelerator cells results in a significant reduction in the amount of magnetic material required to accelerate the ion beam. However, the induction cell drive requirements are very different and much more complex than those in a linear accelerator. 
The first major difference is the repetition rate requirement for the modulators. The repetition rates for a recirculator are determined by the time it takes the ion beam to traverse one lap of a ring. This time depends on the mass and kinetic energy of the ion as well as the circumference of the ring. Figure 1 is a plot of the required repetition rates for various ion masses in a driver with a ring circumference of 2 kilometers. This time period can be as short as $10-20 \mu \mathrm{s}$ for a driver-scale recirculator. In addition, the velocity of the ions increase as they are accelerated, thus reducing the amount of time required to traverse a ring from one lap to the next. The time required for an ion to complete the first lap could be $100 \mu$ s with the last lap requiring only $15 \mu$ s.

The primary objective of the heavy-ion driver is to deliver the full energy of the ion beam to the fusion target in a few 10's of nanoseconds. Stability criteria on the maximum amount of transportable current in an alternating-gradient quadrupole transport system limit the current that can be transported at the lower energies for a given quadrupole field.[3] For this reason, the ion beam is compressed to increase the current as the particle energy increases. In the recirculator, this compression occurs continuously throughout acceleration. In order to maximize the efficiency of the recirculator, the pulse duration of the acceleration potential generated by the modulators should closely track the duration of the beam pulse as it is compressed. In a driver scale recirculator the pulse duration in a single ring can change by an order of magnitude, e.g. $2.5 \mu$ s to $250 \mathrm{~ns}$, during the acceleration sequence.

An example of the desired pulse format is shown in Fig. 2. Although there are several possible formats that might be used, a variable pulse duration was shown to be the most desirable on the basis of beam physics and accelerator efficiency. [3]

An acceleration format with pulse width agility is desirable for two reasons. The first reason is that pulse agility allows a constant and more gentle compression of the beam during the acceleration sequence. Elimination of abrupt changes in beam size and velocity eases some of the physics concerns associated with maintaining the ion beam quality.

The second reason is that the magnetic core losses are significantly reduced by continuously decreasing the pulse duration. As the acceleration pulse gets shorter the peak flux density used in the core becomes less resulting in a significant reduction in overall losses. Figure 3 is a graph of the induction core losses as a function of pulse number for three different acceleration schedules.

In addition to having an extremely flexible pulse format capability, the induction cell modulator must be capable of driving a time-varying load. This load consists of the ion beam in parallel with the nonlinear magnetic material in the induction cell which must be reset after each acceleration pulse. An inverse voltage and current must be supplied 
to reset the magnetic material. Insufficient reset would allow saturation of the induction cell core material resulting in little or no voltage appearing at the acceleration gap. The amplitude of the reset pulse is dependent on the time available for reset because $\int V d t$, where $V$ is the amplitude of the modulator output, must be equal for the both main accelerating pulse and the reset pulse.

\section{MODULATOR DEVELOPMENT}

\subsection{Objectives}

The use of heavy-ion accelerators as drivers for inertial fusion is at least $20-30$ years in the future based on the present development plans for inertial fusion energy (IFE). The purpose of present development work is not to develop a modulator with the capabilities that we believe a modulator will need in the year 2020, but instead to determine the feasibility of the modulator concept based on present day technology and to develop the capability necessary to build a recirculator in the near term as part of an overall driver development program. Presently the most immediate test of a recirculator is likely to be on the proposed ILSE accelerator to be built at LBL. This modulator development work is specifically focused on developing a modulator that can answer the needs of the proposed ILSE recirculator experiment in several years. For this experiment, we estimate that the modulator must be able to supply $50-100$ pulses to drive an induction accelerator cell at repetition rate from $100-200 \mathrm{kHz}$ at voltages on the order of $5 \mathrm{kV}$.

\subsection{Development Plan}

The development of this technology is being undertaken in a series of incremental steps. The first step was to develop a conceptual circuit topology for generating the acceleration pulse and resetting the magnetic material in the induction cell. This concept was then validated using computer modeling and bench top testing. The first significant testing of the concept consisted of a modulator with two devices in series and two devices in parallel. This testing was quickly followed by the design and fabrication of a modulator with four parallel strings of MOSFETs each with six devices in series. This $6 \times 4$ modulator is presently being tested and evaluated. The next step in the development is to build a modulator capable of meeting the ISLE recirculator requirements.

\subsection{Circuit Description}

The performance requirements dictated by the recirculator are so challenging that the choices available for the modulator technology are limited. There are few switch 
choices available with the capability of operating at several $100 \mathrm{kHz}$ and opening as well as closing. Several solid-state switch types were evaluated and power MOSFETs were selected as the basis for our initial development work. Based on power MOSFET technology we have developed a circuit topology that is capable of driving a nonlinear magnetic load at 100's of kilohertz and providing the energy required for reset between pulses.

The modulator circuit components can be grouped into four functional units, i.e. energy storage, switching, reset and load. The diagram in Fig. 4 shows a simplified schematic of the modulator and its functional units. The energy storage unit supplies enough energy to provide a flat voltage pulse to the nonlinear load for $\approx 1 \mu \mathrm{s}$. The switch unit, which is a series-parallel combination of MOSFET switches, controls the flow of energy to the load. It has the capability to both initiate and interrupt current flow at repetition rates $>100 \mathrm{kHz}$. The load is a nonlinear magnetic material, Metglas, in parallel with the ion beam. In early recirculator experiments, the ion beam load will be insignificant compared to the magnetic load. This reset portion of this circuit recovers the energy stored in the magnetic field of the induction core and uses it to reset the core material before the next pulse arrives.

The gate drive circuitry is a significant part of the modulator both in terms of cost and performance. The rise and fall times of the gate drive circuits are critical to the successful operation of these series-parallel stacks of MOSFETs. A fiber optic gate drive system was developed to provide unlimited flexibility in pulse widths and to provide precise control over the rise and fall times of each gate signal.

\subsection{Modulator Packaging}

A unique packaging configuration was chosen to facilitate efficient transfer of energy to the induction cell and thus avoid reflections due to impedance mismatches. This efficient energy transfer is accomplished through closely coupling the modulator to the load and making the modulator an integral part of the induction cell. This also provides a very low impedance drive to the cell which helps suppress any longitudinal beam instabilities that result from finite cell impedances. A picture of the cell packaging is shown in Fig. 5. Four parallel stings of series power MOSFETs are shown assembled on the outer radius of a magnetic core.

\subsection{Performance status}

The first demonstration modulator has been built and is presently being evaluated. This modulator $(6 \times 4)$ has operated at $3 \mathrm{kV}, 160 \mathrm{~A}, 100 \mathrm{kHz}$ and pulse durations of $0.4-1 \mu \mathrm{s}$ as shown in Fig. 6. The modulator has performed as expected and the next 
version is being designed using the latest in MOSFET technology to achieve the voltages $(5 \mathrm{kV})$ and currents $(1 \mathrm{kA})$ required for a recirculator on ILSE.

\section{CONCLUSION}

Early test results on our $6 \times 4$ modulator indicate that the high repetition rates and pulse to pulse agility desired for a recirculator are feasible. There is a high degree of confidence that the performance required for near term recirculator experiments can be achieved with existing MOSFET technology. Modulators for a driver scale recirculator will require much greater voltages $(\approx 100 \mathrm{kV})$ than the $5 \mathrm{kV}$ we are attempting to achieve for an ILSE scale recirculator. Significant innovation and development will be necessary to achieve these higher voltages at affordable costs.

\section{ACKNOWLEDGMENT}

Work performed under the auspices of U.S. Department of Energy by Lawrence Livermore National Laboratory under contract W-7405-ENG-48. 


\section{FIGURE CAPTIONS}

1. Modulator repetition rates required for various mass ions in a recirculator with a $2 \mathrm{~km}$ circumference.

2. Example of pulse format that might be required for a recirculator.

3. Losses on each pulse for three different acceleration schedules where A) $t_{p}=$ constant, B) $\left.t_{p}=b^{-1}, C\right) t_{p}=b^{-2}$ and where $t_{p}$ is the pulse duration and $b=v / c$.

4. Simplified schematic of high repetition rate modulator.

5. Photo of $6 \times 4$ modulator.

6. Cell voltage and reset current during $100 \mathrm{kHz}$. 


\section{REFERENCES}

[1] H. C. Kirbie, G. J. Caporaso, M. A. Newton, and S. S. Yu, "Evolution of HighRepetition-Rate Induction Accelerators Through Advancements in Switching," Proc. Linear Accelerator Conference, Ottawa, Ontario, Canada, August 24-28, 1992, 595.

[2] J. J. Barnard, A. L. Brooks, J. C. Clay, F. Coffield, F. Deadrick, L. V Griffith, A. R. Harvery, D. L. Judd, H. C. Kirbie, V. K. Neil, M. A. Newton, A. C. Paul, L. L. Reginato, G. E. Russell, W. M. Sharp, J. Wilson, and S. S. Yu, "Study of Recirculating Induction Accelerators as Drivers for Heavy Ion Fusion," Lawrence Livermore National Laboratory, Report No. UCRL-LR-108095, May 1992.

[3] E. Lee, T. Fessenden, and L. Laslett, "Transportable Charge in a periodic Alternating Gradient System," IEEE Trans. of Nucl. Sci. NS-26, 2489 (1985). 


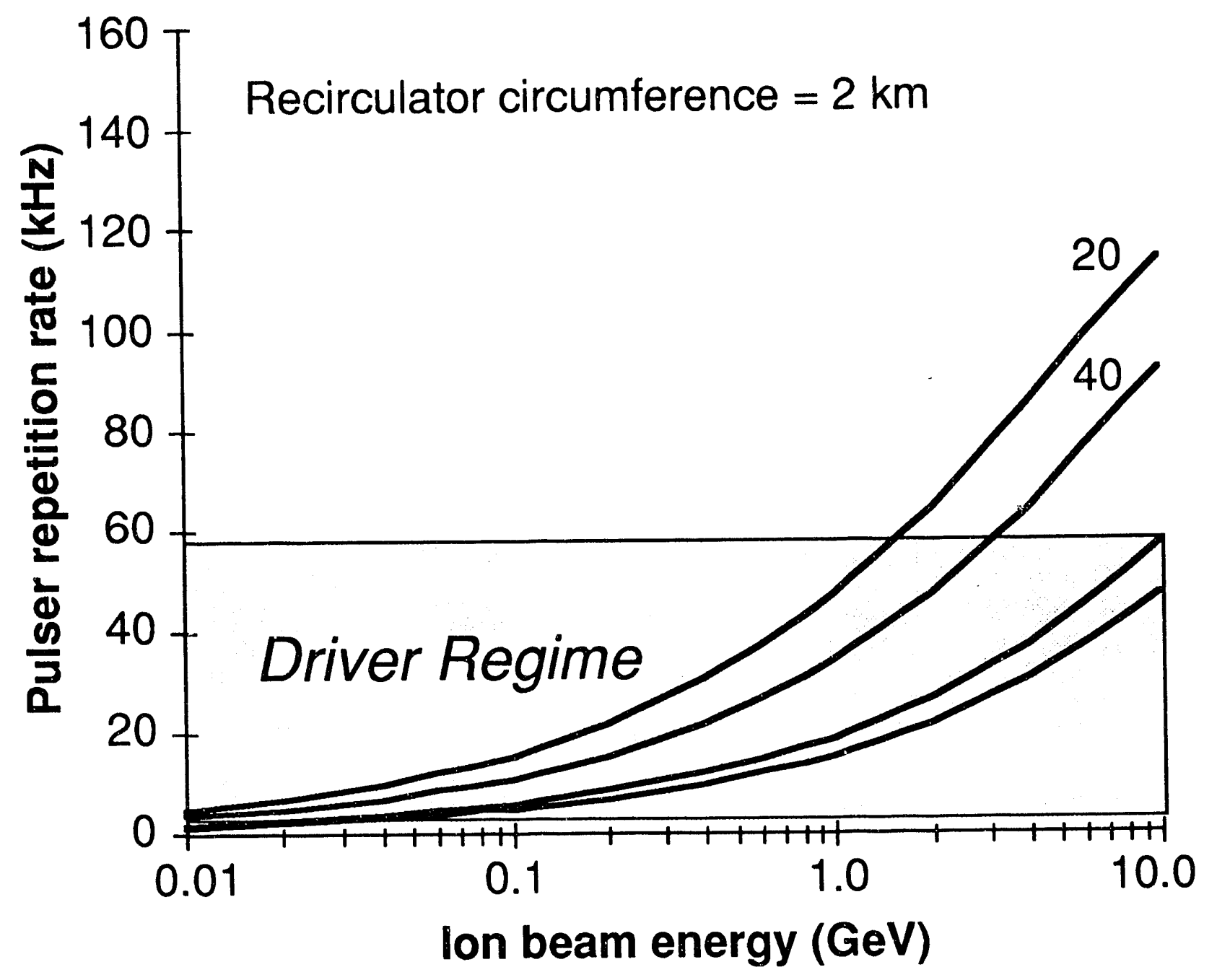

1. Modulator repetition rates required for various mass ions in a recirculator with a $2 \mathrm{~km}$ circumference. 

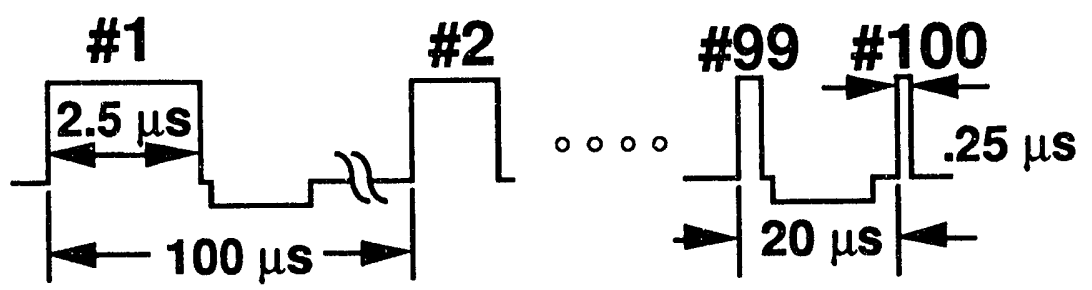

2. Example of pulse format that might he required for a recirculator. 


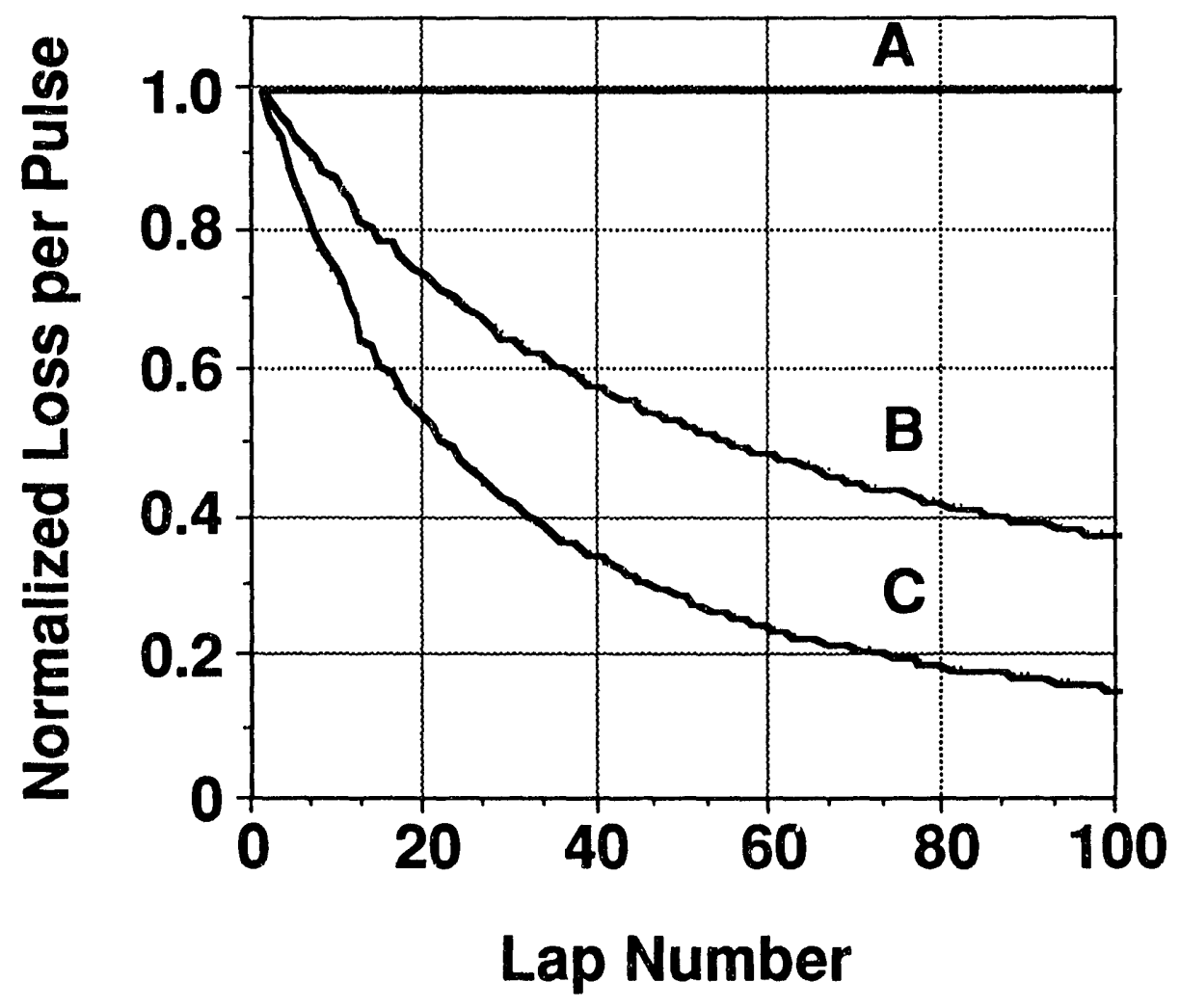

3. Losses on each pulse for three different acceleration schedules where A) $t p=$ constant, $\left.B) t p=b^{-1}, C\right) t p=b^{-2}$ and where $t p$ is the pulse duration and $b=v / c$. 


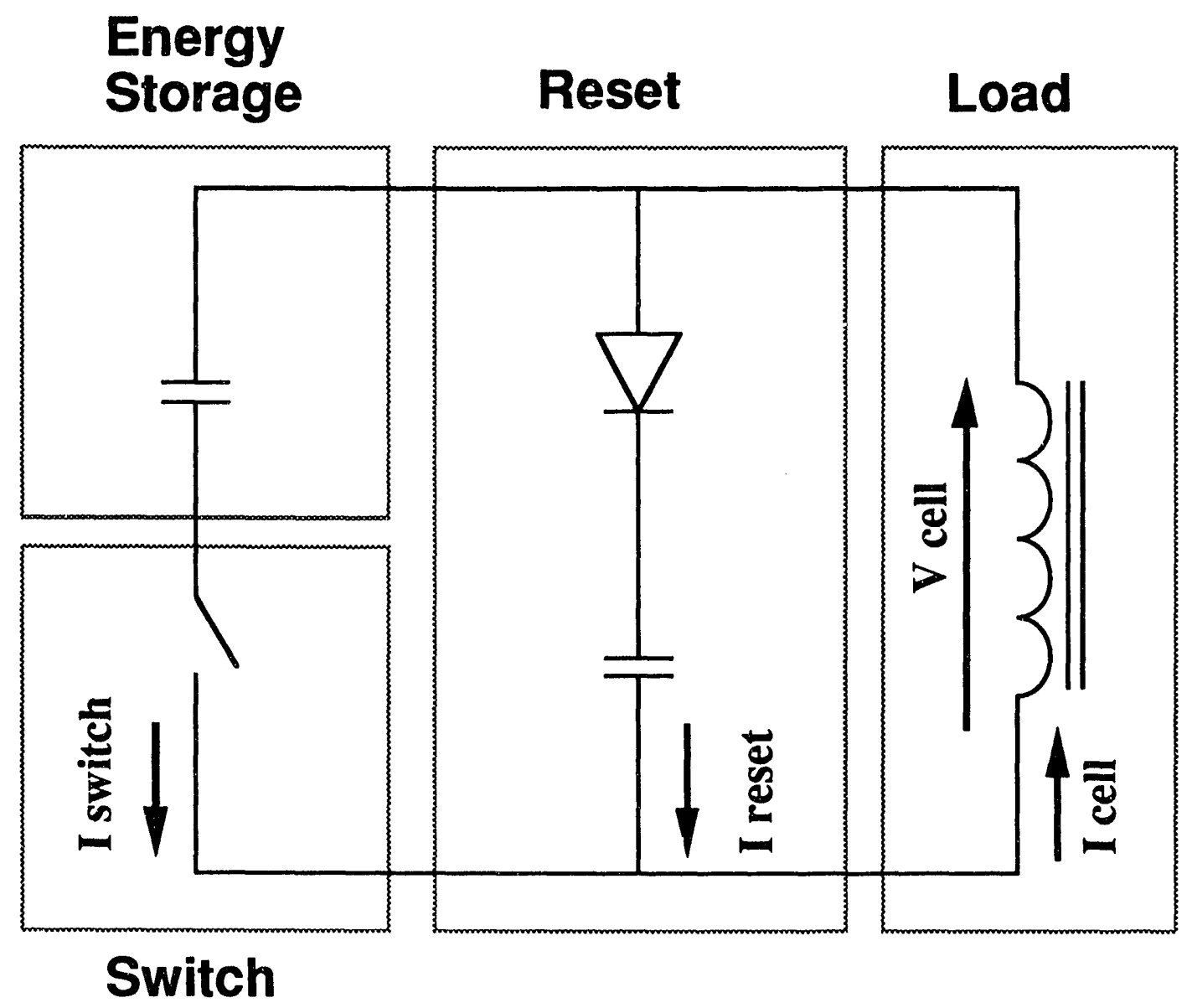

4. Simplified schematic of high repetition rate modulator. 


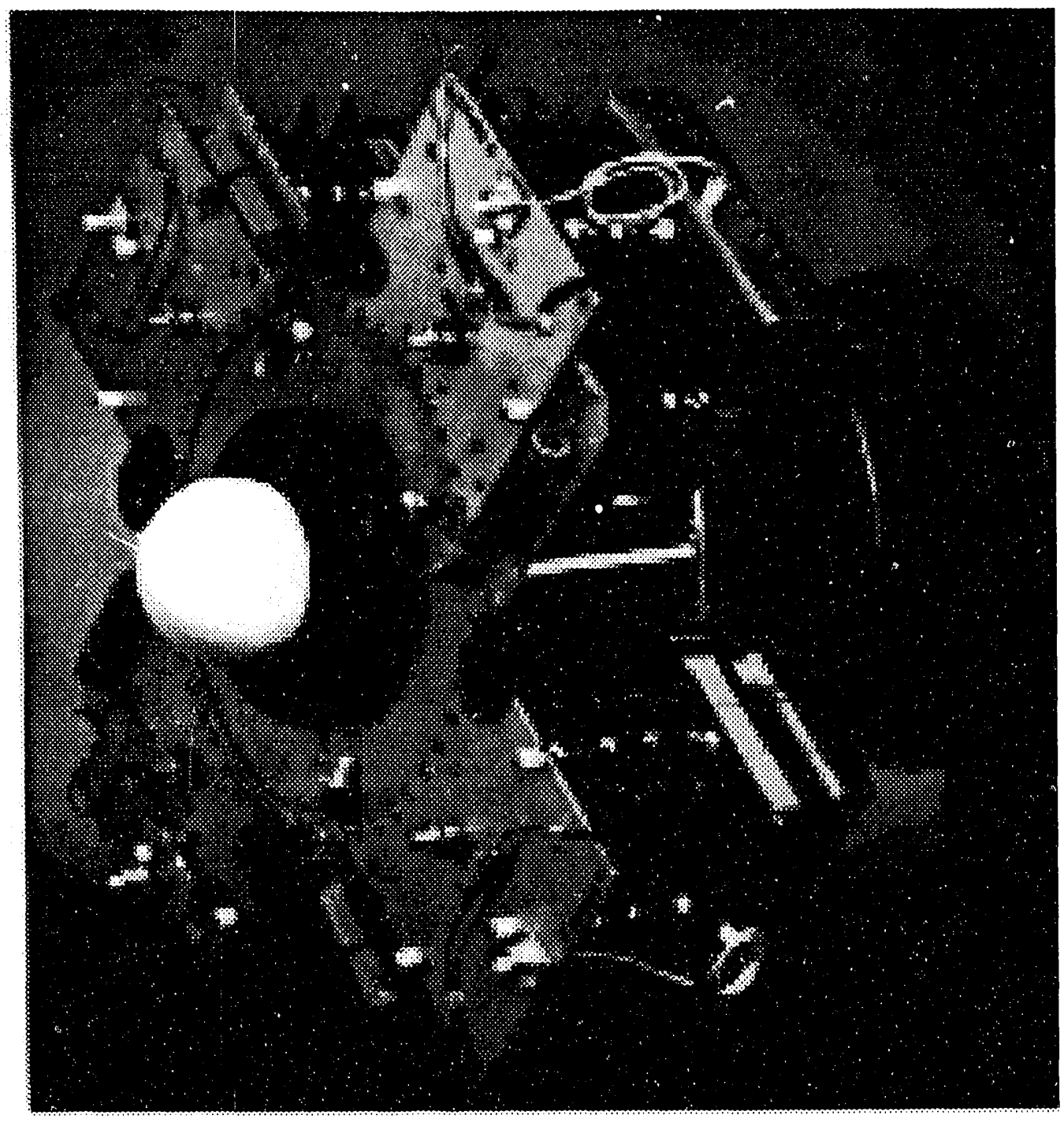

5. Photo of $6 \times 4$ modulator. 


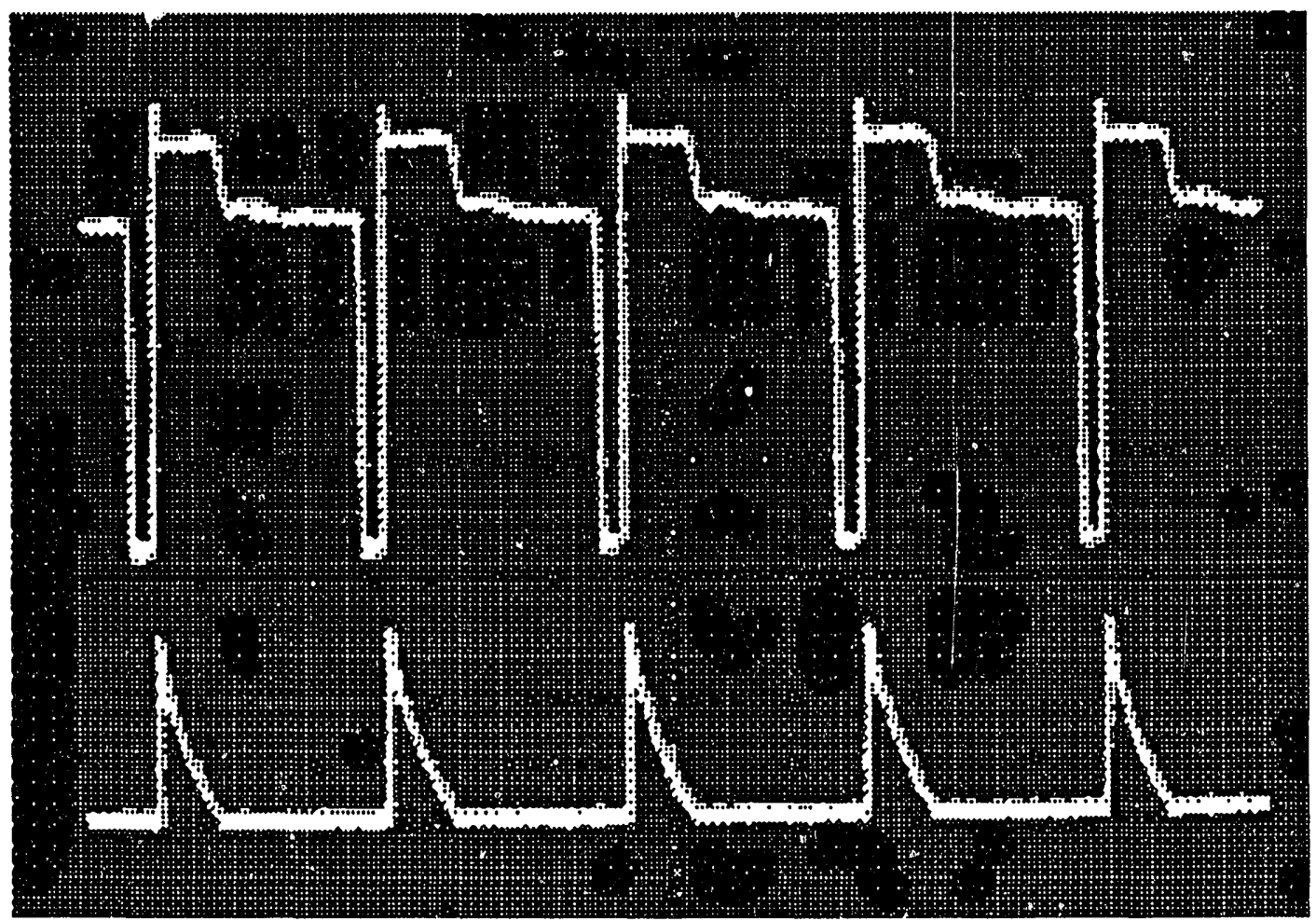

6. Cell voltage and reset current during $100 \mathrm{kHz}$. 

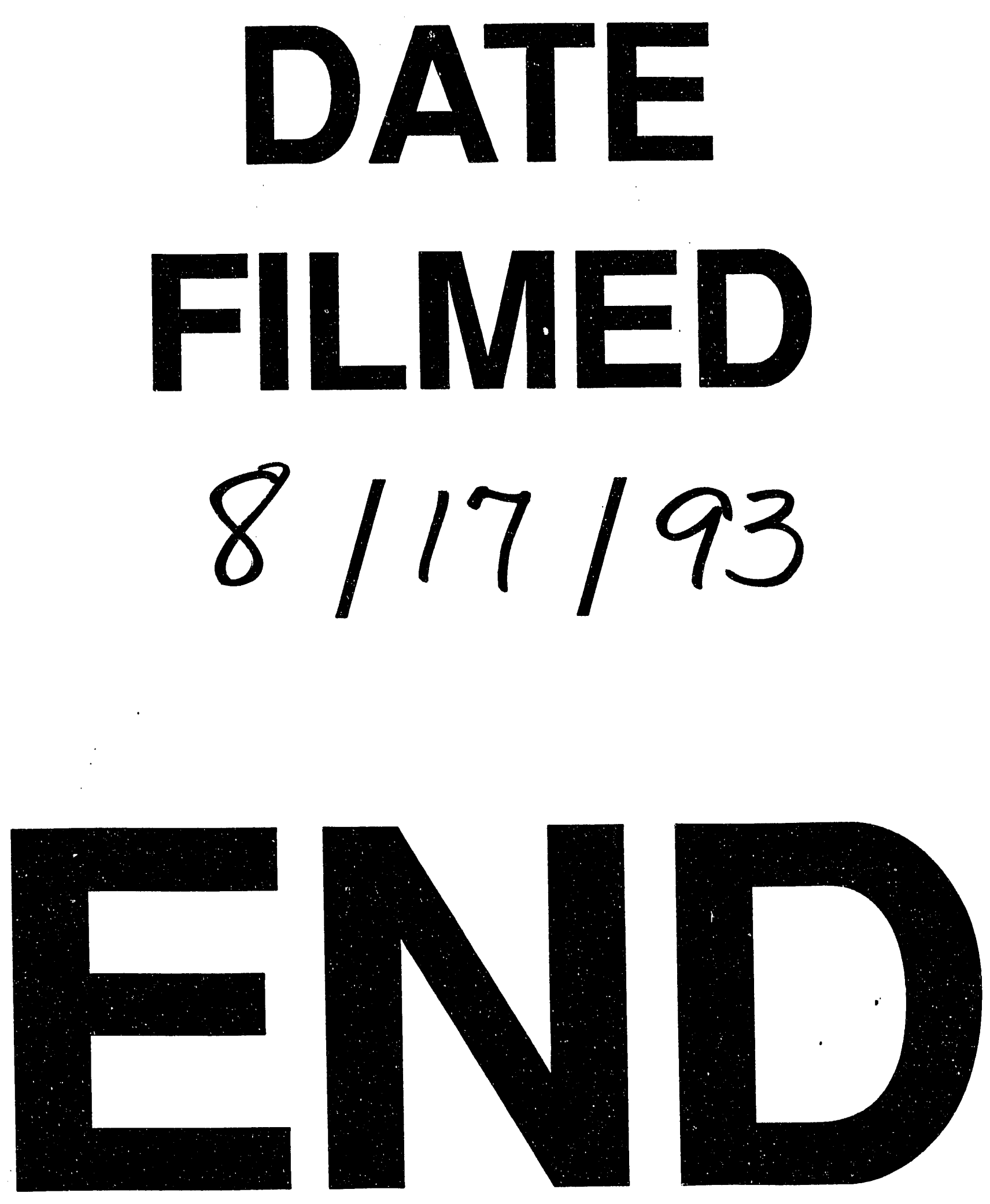
